\title{
The impact of ultrasound Doppler studies on clinical cardiology. A critical appraisal
}

\author{
H.-P. KRayenbueHL and R. JenNi \\ Medical Policlinic, Cardiology, University Hospital Zurich, Switzerland
}

KEY WORDS: Doppler echocardiography, valvular stenoses and insufficiencies, shunts.

In February 1982 the study group of the American Heart Association for 'optimal resources for ultrasonic examination of the heart' made the following statement: 'Various forms of ultrasound using the Doppler principle are currently under development for cardiologic applications. While these appear as promising developments they are not widely accepted and cannot be recommended for general use with diagnostic imaging ${ }^{\text {(1). Since }}$ that time the interest in Doppler studies for characterizing blood flow in the heart and the great vessels has been increasing and this great interest is reflected by the publication of roughly 500 papers on this subject. Despite this enthusiasm, it appears appropriate to ask several questions concerning the place and merits of Doppler echocardiography in diagnosis, quantification and management of heart disease. Our armamentarium of non- or minimally invasive tests is already large and hence we may ask whether the supplementary information we can get from Doppler echocardiography is really essential in clinical cardiology. Does this new technique really contribute to decision-making or does it solely add to redundancy and to overlap of procedures for many common diagnostic problems?

With this in mind we shall examine the various areas where Doppler echocardiography has mainly been used. Emphasis will be placed primarily on problems regarding clinical cardiology in adult patients.

\section{Valvular stenoses}

Most Doppler studies which deal with the diagnosis of valvular stenoses have reported excellent sensitivity and specificity. There is no

Received 13 August 1984 and in revised form 13 November 1984.

Address for correspondence: H.-P. Krayenbuehl MD, Medical Policlinic of the University, Cardiology, $\mathrm{CH}-8091$, Zurich, Switzerland. doubt that Doppler echocardiography is valuable for differentiating functional pulmonary or aortic systolic murmurs from mild pulmonary or aortic valvular stenoses on a yes or no basis. This differentiation which may be difficult to accomplish with other noninvasive methods is of importance in view of antibiotic prophylaxis which would have to be recommended in patients with an organic lesion but not in patients with a functional murmur.

In patients with aortic stenosis the attempts to quantify the systolic peak pressure drop by a simplified version of the Bernoulli equation* have not added importantly to decision making in this setting. This is because the correlations with catheterization data are not close enough; some workers have reported systematic and variable underestimation of the peak pressure drop by Doppler ${ }^{[2,3]}$ and in other studies ${ }^{[4,5]}$, the large scatter of the gradients obtained by Doppler within the critical range of 40 to $60 \mathrm{mmHg}$ precludes decision-making in regard to advising surgery in individual patients.

In patients with valvular pulmonary stenosis the application of the simplified Bernoulli equation for the quantification of the peak transvalvular pressure drop is probably less appropriate than in patients with valvular aortic stenosis for the following reason: In valvular pulmonary stenosis with intact ventricular septum there may be a more or less marked infundibular narrowing producing a systolic pressure gradient between the corpus of the right ventricle and the subvalvular region in addition to the transvalvular gradient ${ }^{16,7]}$. Hence the velocity of systolic blood flow proximal to the valvular stenosis $\left(V_{1}\right)$ may not be negligible. The omission of the prestenotic flow velocity in the

${ }^{*} P_{1}-P_{2}=4 \times\left(V_{2}^{2}-V_{1}^{2}\right)$; where $P_{1}-P_{2}=$ pressure drop $(\mathrm{mmHg})$. $V_{1}=$ prestenotic velocity $\left(m^{-1}\right)$ and $V_{2}=$ poststenotic velocity $\left(\mathrm{m} \mathrm{s}^{-1}\right) . V_{1}$ is generally neglected. 
Bernoulli equation would then lead to an overestimation of the gradient by Doppler.

In mitral stenosis the mean pressure drop during diastole evaluated by Doppler generally correlates well with the mean pressure drop measured at catheterization $^{[8,9]}$. However, the diastolic mean pressure drop is of limited usefulness for assessing the severity of mitral stenosis because it is heavily influenced by the actual flow rate. The preferred measure is the diastolic mitral valve area (MVA). Recently there has been an attempt ${ }^{[10]}$ to calculate MVA from echo-Doppler derived data using the aortic systolic maximum velocity integral (ASVI), the mitral diastolic maximum velocity integral (MDVI) and the cross-sectional area of the aorta $\left(\mathrm{A}_{\mathrm{ao}}\right)\left[\mathrm{MVA}=\left(\mathrm{ASVI} \cdot \mathrm{A}_{\mathrm{ao}}\right) / \mathrm{MDVI}\right.$. MVA determined in this way correlated with the MVA based upon invasive data (revised Gorlin formula) with a correlation coefficient of 0.79 . This correlation coefficient is inferior to those reported for the comparisons between MVA determined from cross-sectional echocardiography and MVA obtained at catheterization $(0 \cdot 89-0 \cdot 95)^{[11-13]}$ or at surgery $(0.92)^{[14]}$. Hence Doppler has not improved the accuracy of determining MVA in mitral stenosis noninvasively. In contrast to Doppler, cross-sectional echocardiography allows quantitation of MVA regardless of the presence of mitral regurgitation and is sufficiently reliable for the clinical decision whether surgery should be advised or not.

\section{Valvular insufficiency}

Generally speaking, the presence or absence of valvular insufficiency is reliably determined by Doppler echocardiography. Among the noninvasive techniques, Doppler is the only positive way of identifying valvular regurgitation. Of particular clinical value is the technique for correct characterization of an apical systolic murmur in aortic stenosis (additional mitral insufficiency?) and for the detection or exclusion of tricuspid insufficiency in the presence of mitral insufficiency. Moreover, we have found Doppler echocardiography useful in differentiating whether a left parasternal diastolic decrescendo murmur was due to aortic insufficiency, pulmonary insufficiency or a venous hum. Clinically silent regurgitation may also be detected by Doppler: In 15 out of 17 patients with angiographically proven aortic insufficiency in whom no diastolic murmur was heard at auscultation, Saal et al..$^{[15]}$ have detected aortic reflux by Doppler echocardiography. In the same 17 patients $M$-mode echocardiography allowed the diagnosis of aortic insufficiency in only 7. Hence in this setting, Doppler echocardiography has been revealed as being significantly more sensitive than the $\mathrm{M}$-mode technique for detecting aortic insufficiency.

For the quantification of valvular insufficiency a variety of indices derived from Doppler studies has been proposed. The degree of regurgitation in $A V$ valve insufficiency has been evaluated from the site in the corresponding atrium or great veins up to which regurgitant flow could be detected and from the increase in early diastolic flow velocity in the inflow tract of the corresponding ventricular chamber. In mitral insufficiency these measures have been shown to correlate with angiographic estimates of mitral regurgitation ${ }^{[16]}$ and in tricuspid insufficiency they were demonstrated to be superior to contrast echocardiography ${ }^{[17]}$. Whether these Doppler derived indexes are really needed for clinical decision-making, is open to question. We feel that a haemodynamically significant tricuspid insufficiency is not missed even when evaluation is only based on the height of the inspiratory v-wave of the jugular venous pulse and that the presence of a moderate to severe mitral insufficiency is very unlikely when there is no abnormal shortening of the left ventricular ejection time. Moreover it is not known whether in the time course of valvular disease a change of severity in AV valve insufficiency is more reliably defined by Doppler derived indexes than by standard clinical, radiographic, mechanographic and echocardiographic measures.

The indices which have been proposed for the quantification of aortic regurgitation are summarized in Table $\mathbf{1}^{[18-21]}$. Most of them were

Table 1 Indices of severity of aortic regurgitation derived from Doppler studies

Ratio of diastolic/systolic instantaneous maximal velocities obtained by multigate Doppler in the ascending aorta (Jenni et al, $1979^{[18]}$ )

Distance from the aortic valves at which diastolic regurgitant flow was detected within the left ventricular cavity (Ciobanu et al. $1982^{[19]}$ )

Ratio of end-diastolic amplitude of retrograde flow/ maximal amplitude of systolic forward flow in the aortic arch (Diebold et al, 1983|20])

Regurgitant aortic valvular area $\left(\mathrm{cm}^{2} \mathrm{~m}^{-2}\right)$ explored by pulsed Doppler (Veyrat et al, 1983 [21]) 
shown to correlate well with semiquantitative angiographic measures of aortic insufficiency. Using multigate Doppler, Jenni et al. ${ }^{[18]}$ have demonstrated that in patients with pure aortic insufficiency the ratio of diastolic/systolic instantaneous maximal velocities in the ascending aorta agreed within $\pm 15 \%$ with the aortic regurgitation fraction obtained from quantitative angio/Fick studies. It should, however, be realized that this Doppler-derived ratio ${ }^{[18}$ is not strictly identical to the haemodynamic, volumetric regurgitant fraction because the numerator includes non-truly regurgitant backflow caused by the diastolic coronary blood flow and the denominator does not take into account the systolic portion of coronary flow.

\section{Valvular prostheses}

In contrast to the limited clinical significance of the quantification of the severity of stenoses in native valves by the calculation of the pressure drop by the simplified Bernoulli equation the finding of an abnormally high gradient in prosthetic valves is important for diagnosing prosthetic valve dysfunction. In this setting, Doppler studies clearly may have an impact on decision-making. Moreover, Doppler echocardiography has proven useful for the localization of the site of regurgitation in prosthetis valves, especially in bioprostheses when one wants to know whether reflux is trans- or paravalvular.

\section{Left-to-right shunts}

With Doppler echocardiography, the site of leftto-right shunts is easily localized regardless whether it is intracardiac or at the level of the great vessels. Quantification of left-to-right shunts has been attempted by the combined measurements of pulmonary, mitral and/or aortic Doppler velocities $^{[22-25]}$. These studies which have been carried out mainly in paediatric patients produced surprisingly good correlates of shunt determination compared with other methods despite many assumptions in the flow calculations. Whether this rather complex method should generally be recommended, however, appears questionable because there are clearly less complicated techniques with proven reliability for the quantification of left-toright shunts such as the dye dilution method with peripheral intravenous injection of cardiogreen and recording by an ear piece.

\section{Miscellaneous}

There are some specific areas where Doppler echocardiography is of diagnostic interest. In hypertrophic cardiomyopathy with obstruction (pressure gradient), the aortic flow curve is characterized by an early peak followed by a plateau at a lower flow level for the rest of the systole. In contrast the shape of the aortic flow curve in patients without obstruction is similar to that of controls ${ }^{[26]}$. It is only in a subgroup of patients with the apical form of hypertrophic cardiomyopathy that a premature arrest of left ventricular emptying occurs ${ }^{[27]}$.

In patients with pulmonary hypertension, flow curves in the right ventricular outflow tract or in the pulmonary artery have shown a particular pattern which resembles the systolic motion of the pulmonary valve at echocardiography: An early peak is followed by a midsystolic notch and a second slowly rising late systolic peak. From the inverse correlation between the time to peak flow and the pulmonary artery mean pressure the severity of the pulmonary hypertension can be approximated $^{[28]}$.

The estimation of cardiac output from Doppler echocardiographic measurements in the ascending aorta has excited considerable interest recently ${ }^{[22,29,30.31]}$. Although some authors have reported good correlations between Doppler derived cardiac output and invasively measured cardiac output, there are several theoretical and practical problems ${ }^{[32]}$ which may interfere with an accurate determination of cardiac output by Doppler (Table 2). Thus in a recent review on the subject by Schuster and Nanda ${ }^{[33]}$, the view was

Table 2 Problems in estimating cardiac output by Doppler echocardiography in the ascending aorla

Velocity distribution across the ascending aorta may not be uniform (antero-posterior and left-right skewness of the profiles) and hence the measured velocity will depend upon the position of the sample volume

Cross-section of the aorta is not constant during systole and not necessarily circular

Velocity and cross-section are often not measured at the same site

Angle of incidence in the third dimension is unknown

Coronary flow is neglected 
expressed that percent changes in Doppler cardiac output are more reliable than absolute values. If only directional changes of cardiac output can be obtained by Doppler we feel that other less complicated techniques than Doppler echocardiography are better suited to achieve this goal. It should be recalled at this point that changes in cardiac output have been well determined by injecting repeatedly the same amount of dye in a peripheral vein and by recording the dilution curves with a densitometer attached to the ear after it had been made hyperaemic.

In summarizing the place of Doppler echocardiography in today's clinical cardiology it can be said that:

(1) this technique is valuable for defining the origin of various murmurs in valvular and congenital heart disease;

(2) it is helpful for the detection of prosthetic valve dysfunction;

(3) it contributes to the differentiation of various forms of hypertrophic cardiomyopathy and is helpful in making the diagnosis of pulmonary hypertension;

(4) the clinical cardiologist should consider it as an adjunct to the diagnostic armamentarium for specific cardiac problems;

(5) the uncritical use of Doppler echocardiography, especially in areas where the theoretical and practical prerequisites for sound studies are lacking or where there is overlap with already well established reliable techniques, should be discouraged.

\section{References}

[1] Echocardiographic study group. Optimal resources for ultrasonic examination of the heart. Circulation 1982; 65: 423A-31A.

[2] Hatle L, Angelsen BA, Tromsdal A. Non-invasive assessment of aortic stenosis by Doppler ultrasound. $\mathrm{Br}$ Heart J 1980; 43: 284-92.

[3] Lima CO, Sahn DJ, Valdes-Cruz LM et al. Prediction of the severity of left ventricular outflow tract obstruction by quantitative two-dimensional echocardiographic Doppler studies. Circulation 1983; 68: 348-54.

[4] Berger M, Berdoff RL, Gallerstein PE, Goldberg E. Evaluation of aortic stenosis by continuous wave Doppler ultrasound. J Am Coll Cardiol 1984; 3: 150-6.

[5] Hoffmann A, Burckhardt D. Evaluation of systolic murmurs by Doppler ultrasonography. Br Heart J 1983; 50: 337-42.

[6] Kirklin JW, Connolly DC, Ellis FH Jr, Burchell HB, Edwards JE, Wood EH. Problems in the diagnosis and surgical treatment of pulmonic stenosis with intact ventricular septum. Circulation 1953; 8: 849-63.
[7] Lester RG, Osteen RT, Robinson AE. Infundibular obstruction secondary to pulmonary valvular stenosis. Am J Roentgenol 1965; 94: 78-84.

[8] Hatle L, Brubakk A, Tromsdal A, Angelsen B. Non-invasive assessment of pressure drop in mitral stenosis by Doppler ultrasound. Br Heart J 1978; 40: $131-40$.

[9] Stamm RB, Martin RP. Quantification of pressure gradients across stenotic valves by Doppler ultrasound. J Am Coll Cardiol 1983; 2: 707-18.

[10] Robson DJ, Flaxman JC. Measurement of the enddiastolic pressure gradient and mitral valve area in mitral stenosis by Doppler ultrasound. Eur Heart $\mathrm{J}$ 1984; 5: 660-7.

[11] Nichol PM, Gilbert BW, Kisslo JA. Two-dimensional echocardiographic assessment of mitral stenosis. Circulation 1977; 55: 120-8.

[12] Wann LS, Weyman AE, Feigenbaum H, Dillon JC, Johnston KW, Eggleton RC. Determination of mitral valve area by cross-sectional echocardiography. Ann Intern Med 1978; 88: 337-41.

[13] Motro M, Schneeweiss A, Lehrer E, Rath S, Neufeld HN. Correlation between cardiac catheterization and echocardiography in assessing the severity of mitral stenosis. Int J Cardiol 1981; 1: 25-34.

[14] Henry WL, Griffith JM, Michaelis LL, McIntosh CL, Morrow AG, Epstein SE. Measurement of mitral orifice area in patients with mitral valve disease by real-time, two-dimensional echocardiography. Circulation 1975; 51: 827-31.

[15] Saal AK, Pearlman AS, Hossack KF, Janko CL, Scoblionko DP. Silent aortic insufficiency: Improved detection by pulsed Doppler echocardiography (abstract). Circulation 1983; 68 (Suppl III): 240.

[16] Abbasi AS, Allen MW, De Cristofaro D, Ungar I. Detection and estimation of the degree of mitral regurgitation by range-gated pulsed Doppler echocardiography. Circulation 1980; 61: 143-7.

[17] Hatle L, Angelsen B. Doppler ultrasound in cardiology: Physical principles and clinical applications. Philadelphia: Lea and Febiger, 1982.

[18] Jenni $R$, Hübscher $W$, Casty $M$, Anliker $M$, Krayenbuehl HP. Quantitation of aortic regurgitation by a percutaneous 128-channel digital ultrasound Doppler instrument. In Lancée CT, ed. Echocardiology. The Hague, 1979: 241-3.

[19] Ciobanu M, Abbasi AS, Allen M, Hermer A, Spellberg R. Pulsed Doppler echocardiography in the diagnosis and estimation of severity or aortic insufficiency. Am J Cardiol 1982; 49: 339-43.

[20] Diebold B, Peronneau P, Blanchard D et al. Non-invasive quantification of aortic regurgitation by Doppler echocardiography. Br Heart J 1983; 49: $167-73$.

[21] Veyrat C, Lessana A, Abitbol G, Ameur A, Benaim R, Kalmanson D. New indexes for assessing aortic regurgitation with two-dimensional Doppler echocardiographic measurement of the regurgitant aortic valvular area. Circulation 1983; 68: 998-1005.

[22] Valdes-Cruz LM, Sahn DJ. Two-dimensional echo Doppler for non-invasive quantitation of cardiac flow: A status report. Mod Conc Cardiovasc Dis 1982; 51 : 123-8. 
[23] Kitabatake A, Inoue M, Asao M et al. Non-invasive evaluation of the ratio of pulmonary to systemic flow in atrial septal defect by duplex Doppler echocardiography. Circulation 1984; 69: 73-9.

[24] Valdes-Cruz LM, Horowitz S, Mesel E, Sahn DJ, Fisher DC, Larson D. A pulsed Doppler echocardiographic method for calculating pulmonary and systemic blood flow in atrial level shunts: Validation studies in animals and initial human experience. Circulation 1984; 69: 80-6.

[25] Barron JV, Sahn DJ, Valdes-Cruz LM et al. Clinical utility of two-dimensional Doppler echocardiographic techniques for estimating pulmonary to systemic blood flow ratios in children with left to right shunting atrial septal defect, ventricular septal defect or patent ductus arteriosus. J Am Coll Cardiol 1984; 3: 169-78.

[26] Jenni $R$, Ruffmann $K$, Vieli A, Anliker $M$, Krayenbuehl HP. Aortic flow in hypertrophic cardiomyopathy (abstract). Eur Heart J 1984; 5 (Suppl 1): 232.

[27] Murgo JP, Alter BR, Dorethy JF, Altobelli SA, McGranaham GM Jr. Dynamics of left ventricular ejection in obstructive and nonobstructive hypertrophic cardiomyopathy. J Clin Invest 1980; 66: 1369-82.
[28] Kitabatake A, Inoue M, Asao $M$ et al. Non-invasive evaluation of pulmonary hypertension by a pulsed Doppler technique. Circulation 1983; 68: 302-9.

[29] Huntsman LL, Stewart DK, Barnes SR, Franklin SB, Colocousis JS, Hessel EA. Non-invasive Doppler determination of cardiac output in man. Clinical validation. Circulation 1983; 67: 593-602.

[30] Chandraratna PA, Nanna M, McKay C et al. Determination of cardiac output by transcutaneous continuous-wave ultrasonic Doppler computer. Am J Cardiol 1984; 53: 234-7.

[31] Loeppky JA, Hoekenga DE, Greene ER, Luft UC. Comparison of non-invasive pulsed Doppler and Fick measurements of stroke volume in cardiac patients. Am Heart J 1984; 107: 339-46.

[32] Jenni $\mathbf{R}$, Vieli A, Ruffmann K, Krayenbuehl HP, Anliker $M$. A comparison between single gate and multigate ultrasonic Doppler measurements of the velocity pattern in the human ascending aorta. Eur Heart J 1984; 5: 948-53.

[33] Schuster AH, Nanda NC. Doppler echocardiographic measurement of cardiac output: Comparison with a non-golden standard. Am J Cardiol 1984: 257-9. 


\section{Comment by L. Hatle (Trondheim, Norway)}

In their critical review on the role of Doppler in clinical cardiology, it is not difficult to agree with Krayenbuehl and Jenni that the use of superfluous methods should be discouraged and that Doppler should only be used when it is likely that the method will give an answer to a question raised. This requirement is the obvious prerequisite for the use of any technique, invasive as well as non-invasive.

Another question is whether a new technique should, as they suggest, be discarded if it merely gives the same information as a technique in use, even if it does so easier, with less cost, or with less discomfort to the patient.

For a proper evaluation of a new technique one should first be aware of what information actually can be obtained with that technique. Here our experience differs clearly from some of the opinions expressed by Krayenbuehl and Jenni. The present comments will therefore mainly deal with lesions where major differences exist in our views on what the information obtained with Doppler adds to the clinical assessment.

In aortic stenosis continuous wave Doppler gives a better assessment of severity than any other non-invasive technique, and in our experience adequate for decisions about surgery to be made ${ }^{[1,2]}$. The earliest work showed significant underestimation in several cases $^{[3]}$. However, this was all done with the use of frequency estimators and not with the spectral analysis used today. The highest frequencies in the Doppler signal, essential to avoid underestimation, are often much easier to record with spectral analysis $^{[4]}$. Although some underestimation of the pressure drop may still occur, we do not find that to be as critical as described by Krayenbuehl and Jenni for patients with mean pressure drops of $40-60 \mathrm{mmHg}$ or less.

They emphasize the influence of flow across the valve on the pressure drop in mitral stenosis, but this is equally important to consider in aortic stenosis and especially in the patients with mean pressure drops in the range $40-60 \mathrm{mmHg}$ or less, where the degree of obstruction may be from mild to severe regardless of the pressure drop. Hence, in these patients additional indicators of severity should always be considered, regardless of whether the pressure drop is obtained invasively or non-invasively.

The time course of the velocity curve and the pressure drop during systole clearly shows whether a pressure drop in this range is due mainly to high flow across the valve or to the degree of obstruction. In the first case peak velocity is early in systole and with an early decrease, so that velocity in late systole is fairly low. When obstruction is more severe the velocity and the pressure drop are more sustained as the tendency to equalization of pressures during systole is less ${ }^{[1,5]}$.

By use of these criteria, i.e. both the mean pressure drop and the time course and duration of pressure drop during systole, a decision based on Doppler data as to whether surgery should be performed or not has for the last 6 years not been altered by subsequent invasive studies in patients with aortic stenosis in our department. This experience also includes patients with mild aortic stenosis who had an invasive study due to chest pain and significant coronary artery disease.

Even so there are still patients with borderline results where the question of surgery is equivocal. In general it is our experience that invasive studies have not facilitated the decision in these cases, as opposed to a combined assessment including symptoms, left ventricular function and additional lesions. In patients not undergoing surgery, follow-up and repeat Doppler studies have shown fairly rapid progression in some and minor or no change in others.

A similar situation is seen with prosthetic valves where definite malfunction is easily diagnosed with Doppler. With borderline results, repeated tests are necessary to diagnose the presence or absence of malfunction. The fact that patients exist in whom a decision about surgery can be difficult does not imply that Doppler does not add significantly to decision-making in aortic stenosis.

The use of Doppler in aortic stenosis has also shown us that there are several patients with a severity where surgery is indicated, but where the usual clinical signs of a severe lesion are lacking. Diagnosing these may reduce the number of patients with aortic stenosis coming too late to surgery.

In neonates, the use of CW Doppler has over the last 6-7 years proved very helpful in the diagnosis and assessment of aortic as well as pulmonary stenosis and coarctation ${ }^{[6]}$. These are all conditions where the diagnosis and/or assessment at this age may be uncertain or missed with echocardiography alone, and the usefulness of Doppler has more recently been acknowledged also by others ${ }^{[7]}$. 
In pulmonary stenosis Krayenbuehl and Jenni suggest that use of the calculated pressure drop is less appropriate as they are concerned that it may be overestimated by Doppler due to infundibular narrowing. It is in fact very easily shown with Doppler whether there is additional infundibular obstruction or not, and while the velocity prior to an obstruction can be neglected when it is low, this is obviously not done when it is increased ${ }^{[8]}$. With the use of spectral display, both the presence and the degree of even a significant subvalvular obstruction can be shown, as well as the absence or presence of additional valvular obstruction.

The pressure drop calculated from Doppler in pulmonary stenosis has been shown to correlate well with invasive measurements ${ }^{|9|}$. Assessment of severity with Doppler has been most useful in infants, but also in older children and in patients following surgery to detect those with significant residual or recurrent obstruction. In patients with borderline pressure drops, the increase in pressure drop during exercise can be helpful for decisions about surgery.

In mitral stenosis they do not mention the reports showing that estimates of mitral valve area (MVA) can be obtained directly from the mitral flow velocity curve by calculating the pressure half-time ${ }^{[10-13]}$. This correlates well with MVA from catheterization data, is easier to obtain with Doppler than with two-dimensional echocardiography in patients with heavily calcified valves or following commisurotomy and is also independent of mitral regurgitation. Doppler therefore provides us with the pressure drop and the valve area, as well as the diagnosis and degree of additional mitral regurgitation and or pulmonary hypertension (cf, below).

The other method of estimating MVA with Doppler referred to in the review ${ }^{[14]}$ has so far not given equally good results, but the method used for calculating aortic flow was probably not optimal.

In regurgitant lesions Doppler as described, adds significantly to the clinical diagnosis of regurgitation in all four valves. For quantitation, most of the approaches used at present are semi-quantitative and improved methods of quantitation are needed. But we find the semiquantitation of regurgitation by Doppler helpful for clinical and surgical decisions.

Mild to moderate regurgitation is often missed by clinical examination and as is also severe regurgitation ocasionally such as severe aortic regurgitation without a diastolic murmur and severe tricuspid regurgitation without jugular venous $V$-waves. While left ventricular ejection time can be helpful to rule out significant pure mitral regurgitation, this can be less helpful when aortic valve disease or left ventricular dysfunction also is present. It can also be useful to diagnose and assess less severe degrees of mitral regurgitation. Recording a clearly increasing degree of mitral regurgitation has been helpful in decisions about surgery in patients with aortic valve disease and in infants with coarctation in order to avoid additional mitral valve repair or residual significant mitral regurgitation after surgery. In aortic regurgitation, increasing mitral regurgitation may mask derangement of left ventricular function.

For assessment of the severity of aortic regurgitation both the recording of the extension in the left ventricle and the diastolic reversal of flow in the aorta are useful methods. The approach used in their own work referred to $^{[15]}$ is not generally applicable since the instrument used is not generally available. The regurgitant fraction was calculated from the relation between maximal velocity or forward and reverse flow in the ascending aorta, assuming that this was proportional to the volume of forward/reverse flow. This disregards both the effect of heart rate on the regurgitant volume and changes in the diameter in the ascending aorta which in significant aortic regurgitation can be marked. With the pulsed Doppler instruments generally available, it is considered better to assess the relation between forward and reverse flow from the descending aorta where velocities across the lumen and the diameter tend to be less variable ${ }^{[17]}$, and the velocities during systole and diastole are integrated.

One of the great advantages of recording regurgitant jet velocities with Doppler is not considered at all in the review. The maximal jet velocities provide the pressure drop between ventricles and atria in systole and between the great vessels and the ventricles in diastole. This is probably one of the most direct and accurate methods available for non-invasive estimation of pulmonary artery pressures.

In tricuspid regurgitation a good correlation has been found between the right ventricular-right atrial pressure difference obtained from maximal velocities recorded with Doppler and that obtained by pressure recording ${ }^{[17-20]}$. In pulmonary regurgitation similar data have been obtained with equally good correlation for the diastolic pressure difference between the pulmonary artery and the right ventricle (unpublished). With normal right atrial pressure this gives a good estimate of both systolic and diastolic 
pressure in the pulmonary artery. Increased atrial or central venous pressure has to be added to obtain actual pressures ${ }^{[18.19]}$.

With the high frequency of tricuspid and pulmonary regurgitation that can be recorded both in patients with and without pulmonary hypertension ( $89 / 67$ and $83 / 46 \%$ respectively, unpublished data) good estimates of pulmonary artery pressure can be obtained in the majority of patients.

The right ventricular isovolumic relaxation time is also useful to obtain systolic pulmonary artery pressure ${ }^{[21]}$. This can be obtained also with $\mathrm{M}$-mode echocardiography ${ }^{[22]}$, but is at least in adults more easily done with Doppler.

The changes in the pulmonary flow velocity curve ${ }^{[22]}$ we find to be useful indicators of increased resistance in the pulmonary circulation ${ }^{[24]}$. One should only be aware that such changes can also be seen in acute illnesses and for some time after surgery, possibly due to increased sympathetic tone.

In hypertrophic cardiomyopathy they consider the aortic flow velocity curve a useful finding for diagnosing obstruction ${ }^{[25]}$. But a more direct and accurate way is to record the increase in velocity within the left ventricle and to calculate the intraventricular pressure drop ${ }^{[26]}$. In addition the filling abnormalities in this condition are easily shown with Doppler and so are effects of therapy both on filling and on obstruction. While left ventricular filling can be derived from echocardiograms, Doppler seems to be an easier and a more direct way to obtain this.

In shunt lesions pressure differences between chambers or vessels can be obtained ${ }^{[27]}$.

Cardiac output: The variation in flow velocity across the lumen in the ascending aorta as described by Jenni and Krayenbuehl ${ }^{[28]}$ is in agreement with our findings. This can create problems for cardiac output determinations from the ascending aorta in some patients since the recorded velocity may not represent the mean across the lumen. Their recordings however, were made much higher in the ascending aorta than where measurements for cardiac outputs have been made. In the reports referred to ${ }^{[29,30]}$ the diameter of the aortic root was measured together with the maximal velocity above the valve. In our experience this works well in patients where the diameter of the root differs little from that of the orifice. But in patients whose root is wider, overestimations tend to occur probably because the velocity recorded is usually the same as that at the smaller orifice, and the lower velocities closer to the wall are not taken into account ${ }^{[31]}$.

By recording the diameter and the velocity at a level where a flat velocity profile can be expected (i.e. high in the outflow tract or at the orifice) this problem can be avoided. Some reports have shown this to work well ${ }^{[32-34]}$ and that is also our experience.

The referred basis for the suggestion that relative changes are more reliable than absolute values is not very impressive. Krayenbuehl refers to Shuster and $\mathrm{Nanda}^{[35]}$ as expressing the view that relative changes are more reliable. Shuster and Nanda, however, only say that their experience tend to confirm that relative changes have been more reliable, and what they refer to is a report on 3 patients with pacemakers where no measurement of cardiac output, invasive or non-invasive was made ${ }^{[36]}$.

Some more data may still be necessary before the optimal way of recording flow across the various valves with Doppler are agreed upon. But these measurements are important since reliable data will, in addition to cardiac output and shunt sizes, allow estimation of valve areas and regurgitant fractions.

As for their conclusion, many of the useful applications in clinical cardiology are not included. It is not clear in which areas they find 'the theoretical and practical prerequisites for sound studies lacking'. If this is aimed at cardiac output measurements, the theoretical basis for recording this at the orifice is certainly sound.

The practical prerequisites for sound studies are in our view (1) the availability of a Doppler instrument with both pulsed and continuous wave capabilities and with spectral display of the Doppler signal and (2) knowledge about the technique, its capabilities, performance and interpretation of results.

At this stage it also seems artificial to consider the use of Doppler in clinical cardiology separately from that of echocardiography. The two techniques should be used together. They are complementary, each facilitates the performance and interpretation of the other, and the combined results give a better basis for decisions and patient management than either technique alone. Used in close context to clinical examination they can directly confirm or change clinical diagnosis and assessment, and in addition to the help this provides for patient management it can actually serve to strengthen clinical diagnosis. 


\section{References}

[1] Hatle L. Aortic valve stenosis. In: Peronneau P, Diebold B, eds. Cardiovascular applications of Doppler echocardiography. Paris: INSERM 111 1982; 313-22.

[2] Hegrenaes L. Noninvasive assessment of aortic stenosis by Doppler ultrasound. Eur Heart J 1983; 4 (Suppl E): 20 (Abstr 62).

[3] Hatle L, Angelsen BA. Tromsdal A. Noninvasive assessment of aortic stenosis by Doppler ultrasound. Br Heart J 1980; 43: 284.92.

[4] Hatle L. Angelsen B. Doppler ultrasound in cardiology, 2nd ed. Philadelphia: Lea \& Febiger, 1985: 129.

[5] Hatle L. Angelsen B. Doppler ultrasound in cardiology, 2nd ed. Philadelphia: Lea \& Febiger, 1985: 132-3.

[6] Hatle L. Assessment of aortic blood flow with continuous wave Doppler ultrasound in the neonate and young child. J Am Coll Cardiol 1985; 5 (Suppl): 113-9.

[7] Robinson PJ. Wyse RKH, Deanfield JE, Franklin R, Macartney FJ. Continuous wave Doppler velocimetry as an adjunct to cross sectional echocardiography in the diagnosis of critical left heart obstruction in neonates. $\mathrm{Br}$ Heart $\mathbf{J}$ 1984: 52: 552-6.

[8] Hatle L. Angelsen B. Doppler ultrasound in cardiology, 2nd ed. Philadelphia: Lea \& Febiger, 1985: 104.

[9] Oliveira Lima C. Sahn DJ, Valdes-Cruz LM, et al. Non invasive prediction of transvalvular pressure gradient in patients with pulmonary stenosis by quantitative two dimensional echo Doppler studies. Circulation 1983; 67: 886-71.

[10] Hatle L, Angelsen B, Tromsdal A. Noninvasive assessment of atrioventricular pressure halftime by Doppler ultrasound. Circulation 1979; 60: 1096-104.

[11] Hatle L, Angelsen B. Doppler ultrasound in cardiology, 2nd ed. Philadelphia: Lea \& Febiger, 1985: 117

[12] Stamm BR, Martin RP. Quantification of pressure gradients across stenotic valves by Doppler ultrasound. J Am Coll Cardiol 1984; 2: 707-18.

[13] Dennig K, Rudolph W. Doppler-echokardiographishe Bestimmung des Schweregrades der Mitralstenose. Herz 1984; 9 : $222-30$.

[14] Robson DJ. Flaxman JC. Measurement of the end-diastolic pressure gradient and mitral valve area in mitral stenosis by Doppler ultrasound. Eur Heart J 1984; 5: 660-7.

[15] Jenni R, Hübscher W, Casty $M$ et al. Quantitation of aortic regurgitation by a percutaneous 128-channel digital ultrasound Doppler instrument. Ed. Lancée CT ed. The Hague: Echocardiology, 1979: 241-3.

[16] Hatle L, Angelsen B. Doppler ultrasound in cardiology, 2nd ed. Philadelphia: Lea \& Febiger, 1985: 266.

[17] Skjaerpe T. Hatle L. Diagnosis and assessment of tricuspid regurgitation with Doppler ultrasound. In: Rijsterborgh $\mathrm{H}$, ed. Echocardiology. The Hague: Martinus Nijhoff, 1981; 299-304.

[18] Skjaerpe T, Noninvasive estimation of pulmonary artery pressure by Doppler ultrasound. In: Spencer M, ed. Cardiac doppler diagnosis. The Hague. Martinus Nijhoff, 1983: 247-54.

[19] Yock PG. Popp RL. Noninvasive estimation of right ventricular systolic pressure by Doppler ultrasound in paticnts with tricuspid regurgitation. Circulation 1984; 70: 657-62.

[20] Hatle L, Angelsen B. Doppler ultrasound in cardiology, 2nd ed. Philadelphia: Lea \& Febiger, 1985: 172.

[21] Hatle L. Angelsen BAJ. Tromsdal A. Noninvasive estimation of pulmonary artery systolic pressure with Doppler ultrasound. Br Heart J. 1981; 45: 157-65.

[22] Stevenson JG. Kawabori I, Gunteroth WG. Noninvasive estimation of peak pulmonary artery pressure by M-mode echocardiography. J Am Coll Cardiol 1984; 4: 1021-8.

[23] Kitabatake A, Inoue M, Asao M et al. Noninvasive estimation of pulmonary hypertension by a pulsed Doppler technique. Circulation 1983; 68: 302-9.

[24] Hatle L, Angelsen B. Doppler ultrasound in cardiology, 2nd ed. Philadelphia: Lea \& Febiger, 1985: 257-64.

[25] Jenni R. Ruffmann K, Vieli A, Anliker M, Krayenbuehl HP. Aortic flow in hypertrophic cardiomyopathy. Eur Heart J 1984: 5 (Abstr Suppl I): 232 (Abstr 1215).

[26] Hatle L, Angelsen B. Doppler ultrasound in cardiology, 2nd ed. Philadelphia: Lea \& Febiger, 1985: 205-13.

[27] Skjaerpe T. Hegrenaes L, Hatle L. Noninvasive estimation of right ventricular pressure by Doppler ultrasound in VSD. In: Fifth Symposium on Echocardiology. Rotterdam 1983. Ultrasonar Bull. 1983; 92 (A bstr).

[28] Jenni R. Vieli A. Ruffmann K. Krayenbuehl HP. Anliker M. A comparison between single gate and multigate ultrasonic Doppler measurements of the velocity pattern in the human ascending aorta. Eur Heart J (in press).

[29] Huntsman LL. Stewart DK. Barnes SR. Franklin SB. Colocousis JS. Hessel EA. Non-invasive Doppler determination of cardiac output in man. Clinical validation. Circulation 1983; 67: 593-602.

[30] Chandraratna PA. Nanna M. McKay C et al. Determination of cardiac output by transcutaneous continuous-wave ultrasonic Doppler computer. Am J Cardiol 1984: 53: 2347.

[31] Hatle L. Angelsen B. Doppler ultrasound in cardiology. 2nd ed. Philadelphia: Lea \& Febiger. 1985: 317.

[32] Ihlen H. Amlie JP. Dale J et al. Determination of cardiac output by Doppler echocardiography. Br. Heart J. 1984: 51: 5460 .

[33] Lewis J. Kuo L. Nelson J. Limacher M. Quinones M. Pulsed Doppler echocardiographic determination of stroke volume and cardiac output from two-dimensional apical views: clinical validation of two new methods. Circulation 1983: 68 (Suppl III): 229 (Abstr).

[34] Bouchard A. Blumlein S. Schiller NB et al. New Method for the measurement of stroke volume and cardiac output by M-mode continUous wave Doppler. Circulation 1984: 70 (Suppl II): 265 (Abstr).

[35] Schuster AH, Nanda NC. Doppler echocardiographic measurement of cardiac output: comparison with a non-golden standard. Am J Cardiol 1984; 53: 257-9.

[36] Schuster AH. Nanda NC. Doppler echocardiography and cardiac pacing. Pace 1982: 5: 607 12. 